Brit. Heart J., 1965, 27, 199.

\title{
THE PULSE OF AORTIC STENOSIS DURING CHILDHOOD
}

\author{
BY \\ J. F. FARRAR AND R. E. GRAY \\ From The Children's Medical Research Foundation, Royal Alexandra Hospital for Children, Camperdown, New South \\ Wales, Australia
}

Received February 2, 1964

The assessment of the severity of aortic stenosis has been the subject of much clinical research. Because of the changes in severe aortic valve lesions in adults, much consideration has been given to the nature and form of the pulse (Wood, 1958) particularly that in the brachial artery, as observed either by palpation or by the recording of an intra-arterial pulse tracing. Cosby et al. (1962) were unable to find any correlation between the severity of aortic stenosis and the contour of the brachial artery pulse, but Robinson (1963b) thought that the carotid pulse was more reliable, though in children it was not an infallible guide (Robinson, 1963a). All these authors have pointed out how change in cardiac output and peripheral resistance could modify these features.

That the pressure gradient across the aortic valve alone is an unreliable index of the severity of aortic stenosis has been remarked on by Wood (1958) and Cosby et al. (1962). Braunwald et al. (1963) report the instance of a patient who had effort syncope and whose aortic valve gradient was only $35 \mathrm{~mm}$. Hg. Braunwald et al. (1963) further drew attention to the fact that congenital aortic stenosis may be the cause of severe left ventricular obstruction without the symptoms of diminished cardiac reserve that are found in other forms of congenital heart disease.

The difficulties in measuring blood flow in children are well known. The absence of clinical symptoms and signs in what may be at least moderate stenosis increases the difficulty of accurate diagnosis.

Patients with severe aortic stenosis often die in infancy or early childhood. Those with mild lesions survive into adult life, and in middle age may develop calcific aortic stenosis. It is in the intermediate group, especially in childhood, that assessment is difficult. Radiographs and electrocardiograms may give little help in the assessment of the true severity of the disease, and effort syncope and sudden death are real hazards.

Dow (1940), while studying the aortic pulse at various situations in the aorta in dogs, noticed that there was an increase in the peak pressure of the pulse wave as the periphery was approached. Andersson and Porjé (1946) and Kroeker and Wood (1955) also illustrated this phenomenon, and it has subsequently been studied in dogs by McDonald and Taylor (1959), McDonald (1960), and Taylor (1962). Dow on the other hand stated that there was little peripheral alteration in the shape of the pulse wave where there was experimentally produced aortic stenosis. This was confirmed in adults by Wright and Wood (1958). If amplification of the peripheral pulse did occur in aortic stenosis in children, an assessment of the systolic gradient across the valve would give a falsely low impression, and attenuation would further destroy characteristic features. In order to investigate the extent of the above phenomena in children who were undergoing investigation of aortic stenosis, the pulse was studied at various situations along the aorta, and in the iliac vessels. 


\section{SuBJECTS AND MethodS}

There were 10 children, 6 boys and 4 girls between 4 and 12 years, who underwent catheterization of the aorta during or immediately preceding direct left ventricular puncture by the method of Brock, Milstein, and Ross (1956). One girl was discovered not to have aortic stenosis (B.B.). The femoral artery was entered with a Seldinger needle, guide wire, and polyvinyl tube with end lumen; alternatively a "teflon" or nylon No. 5 cardiac catheter with end and side lumens was inserted through a small incision in the artery.

The catheter was connected to a Statham P23 strain gauge manometer via polythene tubing filled with sterile, triple distilled water. Recordings of pressure were made on a NEP direct-writing photographic recorder No. 1165 modified for fast speed and equipped with appropriate amplifiers.

In 5 of these patients, immediately after the catheter was removed, the frequency response of the whole system was measured by applying a transient pressure, then measuring the amount of damping and the periodic time of the resulting oscillations. The resonant frequencies in 4 of the 5 patients varied between $15 \cdot 2$ and 16.0 cycles per' second and in the other patient it was 9.5 cycles per second. The damping ratios varied between $0 \cdot 19$ and $0 \cdot 30$. The frequency response was such that frequencies up to $6 \mathrm{c} / \mathrm{s}$ were recorded with 10 per cent accuracy.

Where possible, pressures were taken in the middle of the ascending aorta at the time of the left ventricular puncture; if it was not possible to pass the catheter proximal to the great vessels the pressure was taken at the summit of the arch. Subsequently, pressures were taken immediately above the diaphragm at the level of the tenth or eleventh thoracic vertebra, immediately below the diaphragm at the level of the first or second lumbar vertebra, and at the bifurcation of the aorta, i.e. at the level of the fourth lumbar vertebra (Fig. 1). In certain instances pressures were also recorded in the common iliac and external iliac arteries.

In those instances in which the catheter was directly inserted, occlusion of the artery around the catheter became necessary to prevent bleeding, and atraumatic ligatures in the form of wide bore polythene tubing, held with artery forceps, were applied.

With the aid of the electronic computer in the Physics Department of the University of Sydney, Fourier harmonic analysis was applied to each set of data, after which individual phase of amplification corrections were applied to each harmonic according to the frequency response measurements.

The foot-to-foot wave velocities were also calculated at various situations along the aorta.

TABLE I

Pressure Measurements in Aortic Valve Stenosis (mm. Hg)

\begin{tabular}{|c|c|c|c|c|c|c|c|c|c|c|c|c|c|}
\hline \multirow{2}{*}{\multicolumn{2}{|c|}{$\begin{array}{l}\text { Patient, sex, } \\
\text { and age }\end{array}$}} & \multirow{2}{*}{$\begin{array}{l}\text { Pulse } \\
\text { rate }\end{array}$} & \multirow{2}{*}{$\begin{array}{c}\text { Left } \\
\text { ventricular } \\
\text { pressure }\end{array}$} & \multicolumn{5}{|c|}{ Aorta } & \multirow{2}{*}{$\begin{array}{l}\text { Common } \\
\text { iliac } \\
\text { S/D }\end{array}$} & \multicolumn{2}{|c|}{ Systolic gradient } & \multirow{2}{*}{\begin{tabular}{|c|} 
Pulse \\
pressure \\
increase
\end{tabular}} & \multirow{2}{*}{$\begin{array}{c}\text { Mean } \\
\text { gradient }\end{array}$} \\
\hline & & & & $\begin{array}{l}\text { Ascending } \\
\text { S/D }\end{array}$ & $\begin{array}{l}\text { Arch } \\
\text { S/D }\end{array}$ & $\begin{array}{l}\text { Level of } \\
T 10, S / D\end{array}$ & $\begin{array}{l}\text { Level of } \\
L 1, S / D\end{array}$ & $\begin{array}{l}\text { Level of } \\
L 4, S / D\end{array}$ & & $\begin{array}{c}\text { At } \\
\text { centre }\end{array}$ & $\begin{array}{c}\text { At } \\
\text { peri- } \\
\text { phery }\end{array}$ & & \\
\hline $\begin{array}{l}\text { J.G. } \\
\text { P.P. } \\
\text { B.B. } \\
\text { R.C. } \\
\text { P.P. } \\
\text { I.B. } \\
\text { M.H. } \\
\text { J.P. } \\
\text { L.T. } \\
\text { J.R. }\end{array}$ & $\begin{array}{lr}M & 7 \\
M & 11 \\
F & 10 \\
M & 4 \\
F & 9 \\
M & 6 \\
F & 10 \\
M & 8 \\
F & 10 \\
M & 8\end{array}$ & $\begin{array}{r}130 \\
130 \\
108 \\
120 \\
108 \\
103 \\
102 \\
89 \\
130 \\
108\end{array}$ & $\begin{array}{l}116 / 14 \\
134 / 6 \\
93 / 3 \\
112 / 3 \\
121 / 11 \\
115 / 15 \\
105 / 5 \\
100 / 2 \\
115 / 2 \\
112 / 5\end{array}$ & $\begin{array}{r}75 / 62 \\
102 / 75 \\
84 / 63 \\
72 / 50 \\
86 / 70 \\
80 / 60 \\
85 / 58 \\
80 / 55 \\
90 / 60\end{array}$ & $\begin{array}{r}80 / 60 \\
108 / 75 \\
97 / 65 \\
74 / 47 \\
104 / 60 \\
85 / 61 \\
92 / 63 \\
80 / 60 \\
77 / 55 \\
92 / 58\end{array}$ & $\begin{array}{r}82 / 60 \\
105 / 74 \\
101 / 65 \\
75 / 48 \\
98 / 67 \\
86 / 58 \\
103 / 63 \\
81 / 58 \\
84 / 53 \\
93 / 62\end{array}$ & $\begin{array}{r}87 / 56 \\
107 / 73 \\
99 / 62 \\
74 / 48 \\
94 / 58 \\
88 / 60 \\
105 / 64 \\
78 / 56 \\
84 / 52 \\
93 / 63\end{array}$ & $\begin{array}{r}85 / 56 \\
108 / 73 \\
105 / 66 \\
67 / 47 \\
104 / 69 \\
90 / 58 \\
108 / 60 \\
85 / 59 \\
87 / 57 \\
96 / 66\end{array}$ & $\begin{array}{c}\overline{110 / 72} \\
101 / 61 \\
\overline{103 / 66} \\
96 / 60 \\
105 / 62 \\
\overline{87 / 51} \\
-\end{array}$ & $\begin{array}{r}41 \\
32 \\
9 \\
40 \\
35 \\
35 \\
20 \\
20 \\
35 \\
32\end{array}$ & $\begin{array}{r}31 \\
24 \\
-8 \\
45 \\
18 \\
19 \\
0 \\
15 \\
28 \\
26\end{array}$ & $\begin{array}{r}9 \\
11 \\
19 \\
-5 \\
21 \\
16 \\
16 \\
6 \\
7 \\
0\end{array}$ & $\begin{array}{r}25 \\
4 \\
32 \\
21 \\
20 \\
6 \\
21 \\
29 \\
24\end{array}$ \\
\hline
\end{tabular}

\section{RESULTS}

The results of the pressure recordings are summarized in Table I beside positions in the aorta at which pressures were recorded. In all instances except one, the peak systolic pressure increased as the periphery was approached. The difference in pulse pressure at the periphery was up to $21 \mathrm{~mm}$. $\mathrm{Hg}$ when compared with the central pulse, and the systolic difference was up to $17 \mathrm{~mm}$. $\mathrm{Hg}$.

In every instance there was attenuation and obliteration of the special features of the pulse waves as shown in the central tracing of Fig. 1.

The results of harmonic analysis for a patient with aortic stenosis (Fig. 2) and of a child who was found to have no aortic valve gradient, revealed in each instance that the increased amplitude was due mainly to an increase in amplitude in the first and second harmonics. It is also noticed that at 


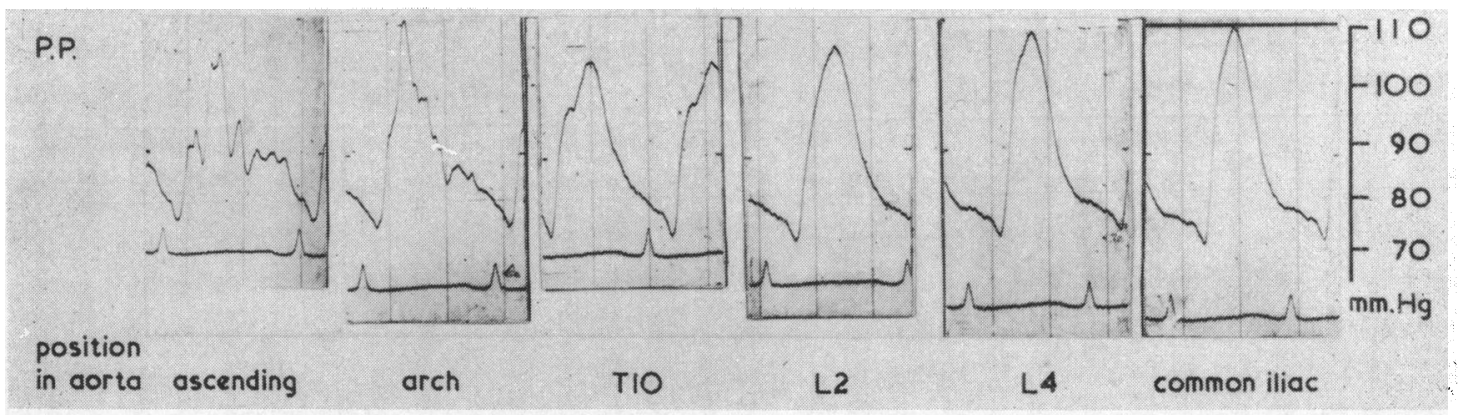

FIG. 1.-Pressure pulse tracings obtained consecutively along the aorta of an 11-year-old boy with aortic stenosis. Anacrotic and dicrotic waves and vibrations are well shown in the central tracing of the ascending aorta. Gradual attenuation and an increase of pulse pressure occurs towards the periphery.

the position corresponding to L4 (bifurcation of the aorta) the harmonics are all rising. Such a phenomenon according to McDonald (1960) indicates that a reflecting site is not more than onequarter of the smallest wave length distal to such a point, i.e. in the case of the fifth harmonic, $8 \mathrm{~cm}$. This would place such a site in the pelvis, an ideal reflecting site with its myriads of small vessels. Pulse wave velocity data (Table II) show that in the ascending aorta the rate is in the region of 6 m./sec., always higher than the thoracic aorta distal to the arch (Fig. 3). These figures are comparable to those obtained in the dog by McDonald and Taylor (1957). A wave travelling at such a speed would travel some $18 \mathrm{~cm}$. in the $\sim 0.03 \mathrm{sec}$. taken for the anacrotic shoulder to appear. If a reflection phenomenon were to explain the anacrotic shoulder itself, rather than the tidal wave as suggested by Bramwell (1937), then this would place a reflecting site in the region of the aortic arch and great vessels (Fig. 4). Table III shows these calculations for 6 patients. In each instance the distance travelled by a wave which moves at the particular foot-to-foot velocity in the time for the appearance of the anacrotic shoulder is, within the experimental error, twice the distance between the valve and the arch.

\section{DisCussion}

Clinically the stenosis in each of the nine patients examined was mild or moderate, but in all cases amplification of the pulse pressure at the periphery did occur.

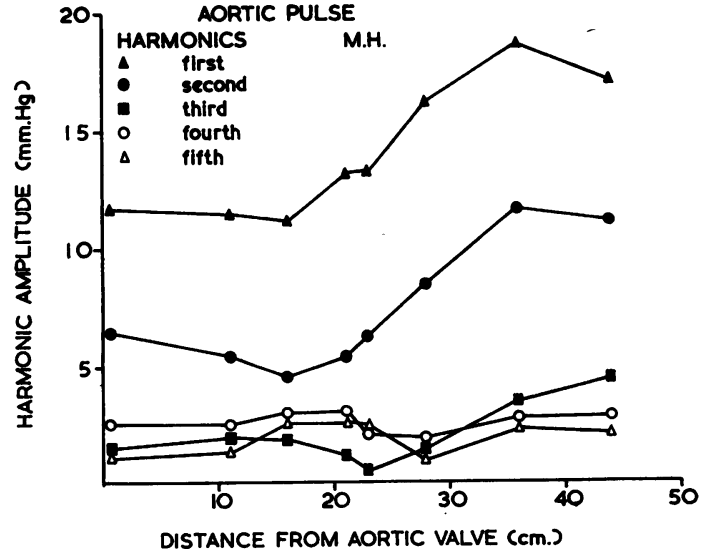

FIG. 2.-Harmonic analysis of the pulse of a 10-yearold girl with aortic stenosis, at various situations in the aorta. Each harmonic waxes and wanes in amplitude according to its wave length and position relative to the main reflecting site, apparently $30-40 \mathrm{~cm}$. from the heart.

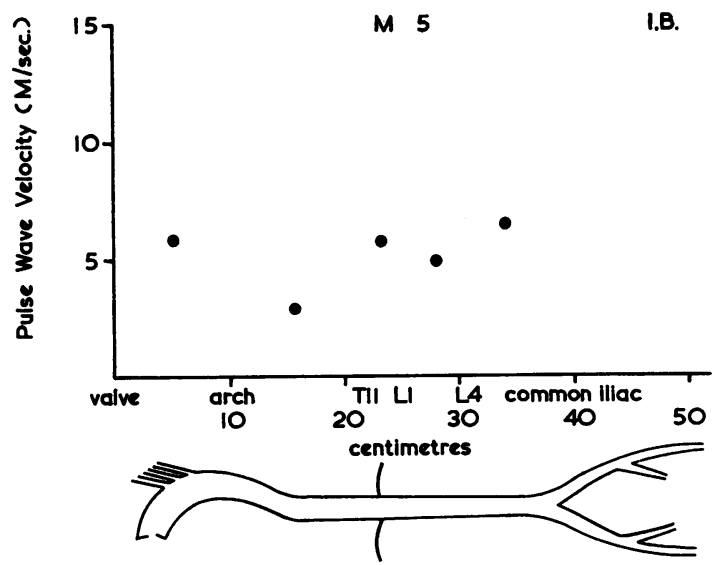

FIG. 3.-Graph showing foot-to-foot velocity along the aorta, of pulse waves of a 5-year-old boy with aortic stenosis (see Table II). 
TABLE II

Foot-to-foot WaVe Velocity at Various Positions in the Aorta (m./sec.)

\begin{tabular}{|c|c|c|c|c|c|c|c|c|}
\hline \multicolumn{4}{|c|}{ Patient } & Valve to Arch & Arch to T 11 & $\mathrm{~T} 11$ to $\mathrm{L} 1$ & $\mathrm{~L} 1$ to $\mathrm{L} 4$ & L 4 to iliac \\
\hline $\begin{array}{l}\text { J.G. } \\
\text { P.P. (M) } \\
\text { B.B. . } \\
\text { R.C. } \\
\text { P.P. (F) } \\
\text { I.B. . . } \\
\text { M.H. }\end{array}$ & $\begin{array}{l}\cdots \\
\cdots \\
\cdots \\
\cdots \\
\cdots \\
\cdots\end{array}$ & $\begin{array}{l}\ldots \\
\ldots \\
\cdots \\
\cdots \\
\cdots \\
\cdots\end{array}$ & $\begin{array}{l}\ldots \\
\ldots \\
\ldots \\
\ldots \\
\ldots \\
\ldots\end{array}$ & $\begin{array}{l}6 \cdot 5 \pm 1 \cdot 9 \\
9 \cdot 0 \pm 3 \cdot 2 \\
6 \cdot 3 \pm 1 \cdot 9 \\
6 \cdot 0 \pm 1 \cdot 8 \\
5 \cdot 8 \pm 7 \cdot 7 \\
6 \cdot 9 \pm 3 \cdot 2\end{array}$ & 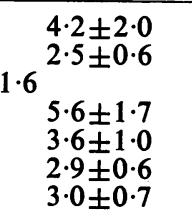 & $\begin{array}{l}3 \cdot 6 \pm 1 \cdot 2 \\
4 \cdot 7 \pm 2 \cdot 0 \\
1 \cdot 2 \pm 0 \cdot 6 \\
4 \cdot 3 \pm 1 \cdot 7 \\
3 \cdot 2 \pm 1 \cdot 5 \\
5 \cdot 7 \pm 2 \cdot 8 \\
4 \cdot 0 \pm 2 \cdot 4\end{array}$ & $\begin{array}{r}4 \cdot 3 \pm 1 \cdot 2 \\
6 \cdot 4 \pm 2 \cdot 5 \\
11 \cdot 3 \pm 4 \cdot 4 \\
2 \cdot 8 \pm 1 \cdot 0 \\
12 \cdot 5 \pm 6 \cdot 0 \\
4 \cdot 9 \pm 2 \cdot 0 \\
4 \cdot 1 \pm 1 \cdot 5\end{array}$ & $\begin{array}{l}6 \cdot 5 \pm 3 \cdot 8 \\
4 \cdot 7 \pm 2 \cdot 0\end{array}$ \\
\hline
\end{tabular}

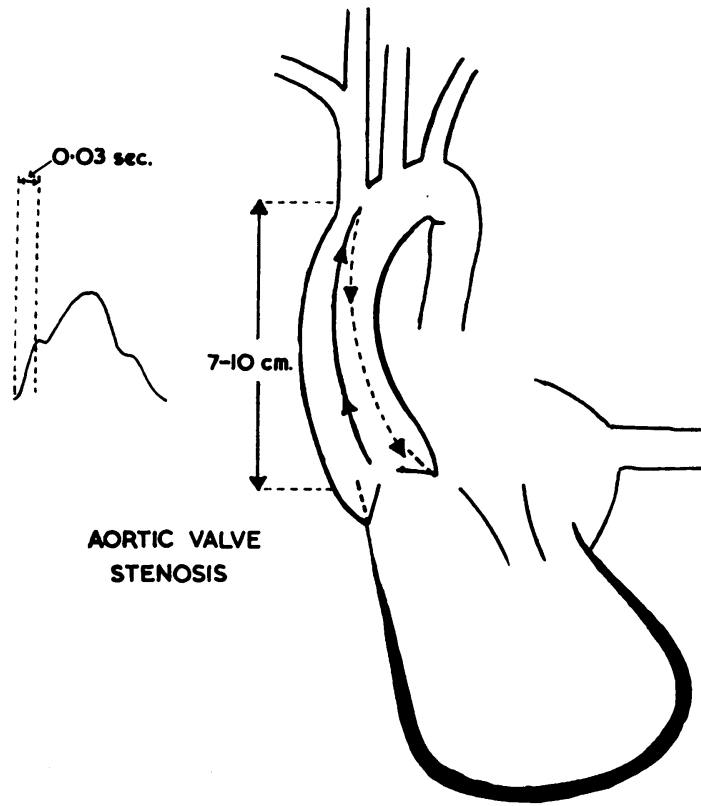

Fig. 4.-Diagram to illustrate possible cause of anacrotic wave of central pulse in aortic stenosis. A wave travelling twice the distance between aortic valve and arch at wave velocity in this region (Table II) would do so in the time taken for the anacrotic shoulder to appear (Table III).

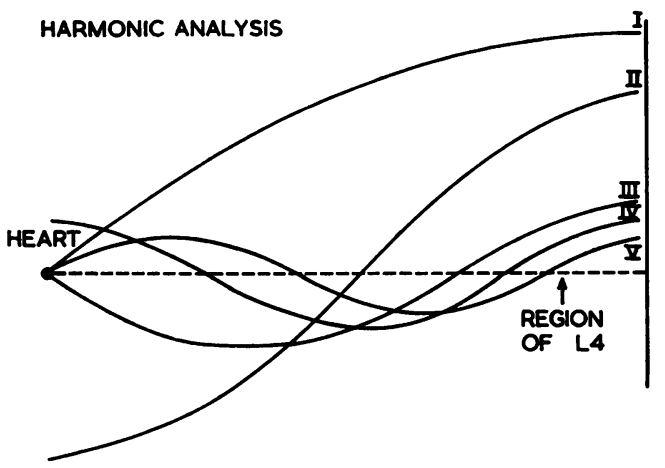

FIG. 5.-Diagrammatic representation of first 5 harmonics of true standing waves arranged about a reflecting point. It can be seen that all the harmonics are increasing in amplitude in the region between the reflecting site and a distance that is one-quarter the wave length of the highest harmonic. The node for the fundamental is represented at the heart, though this is not true of all the harmonics.

TABLE III

Relation between Timing of Anacrotic Notch and Wave Travel in Ascending Aorta

\begin{tabular}{|c|c|c|c|c|c|c|c|}
\hline \multicolumn{3}{|c|}{ Patient } & \multirow{2}{*}{ 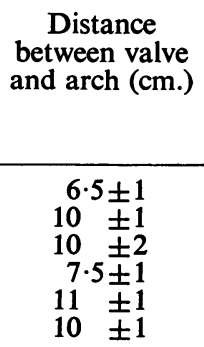 } & \multirow{2}{*}{$\begin{array}{c}\begin{array}{c}\text { Foot-to-foot } \\
\text { wave velocity } \\
\text { between valve } \\
\text { and arch-V } \\
\text { (m./sec.) }\end{array} \\
6 \cdot 5 \pm 1 \cdot 9 \\
9 \cdot 0 \pm 3 \cdot 2 \\
8 \cdot 0 \pm 1.6 \\
6 \cdot 3 \pm 1.9 \\
6 \cdot 0 \pm 1 \cdot 8 \\
6.0 \pm 3.0\end{array}$} & \multirow{2}{*}{$\begin{array}{c}\begin{array}{c}\text { Time delay between } \\
\text { foot of wave and } \\
\text { beginning of } \\
\text { anacrotic notch } \\
\text { t (sec.) }\end{array} \\
0.030 \pm 0.002 \\
0.031 \pm 0.002 \\
0.025 \pm 0.003 \\
0.031 \pm 0.003 \\
0.036 \pm 0.004 \\
0.028 \pm 0.004\end{array}$} & \multirow{2}{*}{ 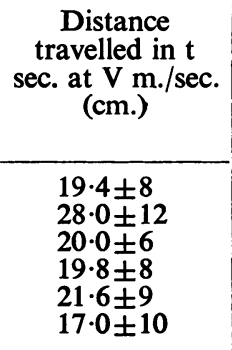 } & \multirow{2}{*}{\begin{tabular}{|c}
$\begin{array}{c}\text { Twice } \\
\text { distance } \\
\text { between valve } \\
\text { and arch (cm.) }\end{array}$ \\
$13 \pm 2$ \\
$20 \pm 2$ \\
$20 \pm 4$ \\
$15 \pm 2$ \\
$22 \pm 2$ \\
$20 \pm 2$
\end{tabular}} \\
\hline $\begin{array}{l}\text { J.G. } \\
\text { P.P. (M) } \\
\text { B.B. } \quad \cdots \\
\text { R.C. } \\
\text { P.P. (F) } \\
\text { S.L. } \quad \text {. }\end{array}$ & $\begin{array}{l}\ldots \\
\ldots \\
\cdots \\
\ldots \\
\cdots\end{array}$ & $\begin{array}{l}\ldots \\
\ldots \\
\ldots \\
\ldots \\
\ldots\end{array}$ & & & & & \\
\hline
\end{tabular}


Taylor (1957a, b) has shown theoretically and experimentally on a hydraulic model that an attenuating line will not support true standing waves. However, he predicted and found relative nodes and antinodes.

In later work on the dog, McDonald (1960) separated the harmonic components of the pulse wave, and was able to show maxima and minima. From his studies, he suggested that the various harmonics of the pulse wave arrange themselves around the periphery as a reflecting site or antinode rather than around the heart as a node. Nevertheless Fig. 2 suggests that the node for the fundamental is near the heart, though this is not true of all the harmonics. This concept is represented diagrammatically in Fig. 5.

The results obtained in the children studied as typified by Fig. 2 indicate the presence of relative nodes and antinodes. It can also be seen that between the tracing taken at L4 and the peripheral reading, all the 5 harmonics are increasing in amplitude. If the pulse waves do arrange themselves around the periphery as an antinode, then this would indicate a reflecting point no more than onequarter of the shortest wave-length (i.e. $8 \mathrm{~cm}$.) away. This strongly suggests the large collection of small vessels in the pelvis as a reflecting site.

Hancock and Fleming (1960) have suggested that the appearance of the anacrotic notch is related to the high velocity jet just distal to the stenotic aortic valve. The possibility of a reflection phenomenon is not eliminated by these observations because the higher harmonics supposed responsible for the smaller anacrotic wave might well be attenuated at more distal situations.

In comparison with the first two, the higher harmonics show only a small change in amplitudes. Thus the arterial system attenuates the higher more than the lower frequencies and most of the energy of the pulse is seen to be contained in the first and second harmonics.

Attenuation of the waves is further borne out by the difference in the shape of the pulse wave at the periphery compared with that in the ascending aorta. The sharp discontinuities in the form of the anacrotic and dicrotic notches have disappeared by the time the periphery is reached. Although in these investigations the catheter was not inserted from above, observations on a circulation model (unpublished data) show that this attenuation or smoothness will still occur if an end-hole catheter is inserted from the centre to a peripheral site, even though a greater length of catheter is thus exposed to vibration. Whether the smoothness varies according to the length so exposed was not determined.

The physical properties of the aorta itself must be considered when explaining the peripheral pulse (Taylor, 1962). It has been shown by Cleary (1962) that while the combined elastin and collagen content of the aorta in humans with non-cardiovascular disease at various ages is contant, the elastin decreases and the collagen increases as the periphery is approached. Our own work on the aortas of children who have died from non-cardiovascular causes confirms this work. This implies greater rigidity at the periphery of the arterial system and therefore increased reflection. This rigidity appears to be related to arterial size and to be greatest in the branches of the aorta. Furthermore, rigidity allows more faithful transmission of the true features of the central pulse which would explain why such are better represented in the carotid arteries rather than in the femoral. To reach the femoral artery the pulse has to traverse the attenuating line of the aorta which contains much elastic tissue.

The suggestion of a reflection phenomenon to explain the anacrotic shoulder of the pulse of aortic stenosis is supported by the preliminary combination of wave velocity data for the central pulse wave with the time delay of the notch. Its prominence in more severe degrees of aortic stenosis would thus be explained by the fact that a greater surface of the aortic valve is presented to the reflected wave, with a consequent increase in the reflection of the reflected wave to travel with the original wave.

It is concluded that less information can be obtained from an examination of a peripheral pulse than of the central pulse in children suffering from aortic stenosis. During the assessment of a child who appears to have severe aortic stenosis, it may be advisable to examine the central pulse tracing 
before the final opinion about the aortic valve is given. Too much emphasis placed on the nature of the peripheral pulse may give a false impression of the severity of the lesion suggesting that it is not so severe. It is therefore important during the examination of the pulse to palpate arteries that are close to the heart to ensure that the pulse has undergone minimal interference.

\section{SUMMARY}

In view of the difficulty of the assessment of aortic stenosis in children, an attempt has been made to investigate the properties of the pulse and any changes that the central aortic pulse may undergo in these patients.

Nine children with aortic stenosis and one who was subsequently discovered to be normal had pressures recorded consecutively along the length of the aorta and beyond its bifurcation.

Considerable attenuation and increase in pulse pressure in the periphery took place in every case and there was an increase in systolic pressure in all but one.

Harmonic analysis of the pulse waves along the aorta shows that the increase is chiefly in the first and second harmonics.

Evidence from harmonic analysis also suggests that there is a reflecting site for pulse waves in the vessels of the pelvis.

Foot-to-foot wave velocities have been calculated at various situations in the aorta. With this information, a reflection phenomenon has been proposed to explain the anacrotic notch of aortic stenosis. The reflecting site would be in the region of the aortic arch and great vessels.

We should like to thank Professor M. G. Taylor of the Department of Physiology, the University of Sydney, for his assistance and advice, as well as Dr. Douglas Stuckey of the Adolph Basser Institute of Cardiology, Royal Alexandra Hospital for Children, Sydney. Our thanks are also due to Mr. John Jackson, of the Adolph Basser Institute of Cardiology, Royal Alexandra Hospital for Children, and Mr. E. C. Hulme and Mr. Trevor Hulme for their engineering assistance.

\section{REFERENCES}

Andersson, B., and Porjé, I. G. (1946). Study on Ph. Broemser's manometer theory for oscillations in the aorta. Acta physiol. scand., 12, 3.

Bramwell, C. (1937). The arterial pulse in health and disease. Lancet, 2, 239, 301, 366.

Braunwald, E., Goldblatt, A., Aygen, M. M., Rockoff, S. D., and Morrow, A. G. (1963). Congenital aortic stenosis. I. Clinical and hemodynamic findings in 100 patients. Circulation, 27, 426.

Brock, R., Milstein, B. B., and Ross, D. N. (1956). Percutaneous left ventricular puncture in the assessment of aortic stenosis. Thorax, 11, 163.

Cleary, E. G. (1962). Collagen. elastin and calcium gradients along the human aorta. Abstracts of the Australian Physiological Society Meeting, May, 1962.

Cosby, R. S., Hedge, B., Amsden, N., and Mayo, M. (1962). A critical review of aortic stenosis. Amer. J. Cardiol., 9, 203.

Dow, P. (1940). The development of the anacrotic and tardus pulse of aortic stenosis. Amer. J. Physiol., $131,432$.

Hancock, E. W., and Fleming, P. R. (1960). Aortic stenosis. Quart. J. Med., 29, 209.

Kroeker, E. J., and Wood, E. H. (1955). Comparison of simultaneously recorded central and peripheral arterial pressure pulses during rest, exercise and tilted position in man. Circulat. Res., 3, 623.

McDonald, D. A. (1960). Blood Flow in Arteries (Monogr. Physiol. Soc. No. 7). Arnold, London.

- and Taylor, M. G. (1957). The phase velocities of harmonic components of the pulse wave. J.Physiol. (Lond.), 137, 87P.

_ and 1 (1959). The hydrodynamics of the arterial circulation. Progr. Biophys., 9, 107.

Robinson, B. (1963a). The carotid pulse. I: Diagnosis of aortic stenosis by external recordings. Brit. Heart J., 25,51 .

— (1963b). The carotid pulse. II: Relation of external recordings to carotid, aortic, and brachial pulses. Brit. Heart J., 25, 61 .

Taylor, M. G. (1957a). An approach to the analysis of the arterial pulse wave. I. Oscillations in an attenuating line. Phys. in Med. Biol., 1, 258.

(1957b). An approach to an analysis of the arterial pulse wave. II. Fluid oscillations in an elastic pipe. Phys. in Med. Biol., 1, 321.

- (1962). Studies in the Travel of Waves in Non-uniform Elastic tubes: The Relation between Cardiac Work and the Construction of the Arterial System. Abstracts of the Meeting of the Australian Physiological Society, May, 1962.

Wood, P. (1958). Aortic stenosis. Amer. J. Cardiol., 1, 553.

Wright, J. L., and Wood, E. H. (1958). The value of aortic and radial pressure pulses in the diagnosis of cardiovascular disorders. Amer. Heart J., 56, 64. 